\title{
Hydrogenated Microcrystalline Silicon: From Material to Solar Cells
}

\author{
N. Wyrsch, C. Droz, L. Feitknecht, M. Goerlitzer, U. Kroll, J. Meier, P. Torres, E. Vallat- \\ Sauvain, A. Shah, M. Vanecek ${ }^{1}$ \\ Institut de Microtechnique, Université de Neuchâtel, \\ Breguet 2, CH-2000 Neuchâtel, Switzerland. \\ ${ }^{1}$ Institute of Physics, Academy of Sciences of the Czech Republic, \\ Cukrovarnicka 10, Prague 6, CZ-16200 Czech Republic
}

\begin{abstract}
Undoped hydrogenated microcrystalline silicon ( $\mu \mathrm{c}-\mathrm{Si}: \mathrm{H})$ layers and solar cells have been deposited by plasma-enhanced chemical vapour at low temperature and at different values of VHF plasma power and silane to hydrogen dilution ratios. Transport and defect density measurements on layers suggest that structural properties (e.g. crystallite shape and size) only marginally influence the electronic transport properties. The latter are influenced strongly by the Fermi level, which depends on the oxygen impurity content. Furthermore, they are best described by the quality parameter $\mu^{0} \tau^{0}$ (deduced from photoconductivity and ambipolar diffusion length). Cell efficiency correlates better with $\mu^{0} \tau^{0}$ than with the defect density as determined from subbandgap absorption. Anisotropy of the transport properties in some $\mu \mathrm{c}-\mathrm{Si}: \mathrm{H}$ is also demonstrated but does not seem to play a major role in $\mu \mathrm{c}-\mathrm{Si}: \mathrm{H}$ cells deposited at high rates under VHF glow discharge conditions.
\end{abstract}

\section{INTRODUCTION}

Microcrystalline hydrogenated silicon $(\mu \mathrm{c}-\mathrm{Si}: \mathrm{H})$ deposited by plasma Chemical Vapour Deposition (CVD) was introduced as early as 1969 by Veprek et Marecek [1]. Although Veprek and co-workers very early studied the effect of oxygen contamination and were able to produce material with a relatively low defect density $[2,3,4]$, it is only recently that these questions have been addressed systematically. Such recent work allowed for a rapid development of $\mu \mathrm{c}-\mathrm{Si}: \mathrm{H}$ as a photovoltaically active material for solar cell applications. Efficiencies in excess of $8 \%$ have been demonstrated on entirely microcrystalline $\mathrm{p}-\mathrm{i}-\mathrm{n}$ cells with no sign of light-induced degradation $[5,6]$. Despite a multitude of activities in the field of $\mu \mathrm{c}-\mathrm{Si}: \mathrm{H}$ layers and cells, and more precisely on the growth of this material $[7,8,9]$, knowledge on some more fundamental aspects, such as electronic transport or defects in the material, is still limited. Among critical properties for the cells performance, optical properties are nowadays the best understood [10, 11]. On the opposite side, the factors limiting transport $[12,13,14]$ and the exact nature of the defects in this heterogeneous material $[15,16]$ remain yet quite a mystery. Improved knowledge in these topics would help optimising solar cells.

$\mu \mathrm{c}-\mathrm{Si}: \mathrm{H}$ is usual deposited by CVD using a strong dilution of silane in hydrogen. $\mu \mathrm{c}-\mathrm{Si}: \mathrm{H}$ is not a unique and well defined material, but can exhibit various forms of microstructure [17], which depend critically on the deposition conditions (i.e. mostly on silane to hydrogen dilution ratio) and substrate [7]. Such variation in material morphology is expected to affect the layer transport properties, the defects density as well as solar cell performance. In our $\mu \mathrm{c}-\mathrm{Si}: \mathrm{H}$ material, hydrogen present during growth bounds mainly at the grain boundary surface [18]. We assume that it is the reason for the very low defect densities observed in $\mu \mathrm{c}-\mathrm{Si}: \mathrm{H}$, due to an almost complete passivation of the grain boundary defects. As a consequence of this low defect density, transport models developed for poly-Si material are not directly applicable to $\mu \mathrm{c}-\mathrm{Si}: \mathrm{H}$.

The objective of this paper is to study transport properties such as dark conductivity $\sigma_{\text {dark}}$, photoconductivity $\sigma_{\text {ph }}$, ambipolar diffusion length $\mathrm{L}_{\mathrm{amb}}$ (measured from steady-state photocarrier grating (SSPG)), diffusion length $L_{D}$ (measured from surface photovoltage (SPV)), $\mu^{0} \tau^{0}$ products, and defect densities in series of $\mu \mathrm{c}-\mathrm{Si}: \mathrm{H}$ layers, and to discuss them in the view of the material structural properties. The comparison of the data obtained under various deposition conditions is used to get insight into the factor limiting transport. The question of a possible 
anisotropy of the transport is thereby also investigated. Finally, performance of solar cells incorporating layers deposited under identical plasma conditions is compared with characteristics of individual layer, so as to identify the most important properties that characterise a material for its application as a photovoltaically active layer within solar cells.

\section{EXPERIMENTAL}

All $\mu \mathrm{c}-\mathrm{Si}: \mathrm{H}$ cells and layers were grown by the very high frequency glow discharge (VHFGD) deposition technique at a temperature around $200^{\circ} \mathrm{C}$. Three series of layers were deposited at a fixed VHF power $(6,7$ and $30 \mathrm{~W})$ at various silane concentrations in hydrogen $(1.25 \%$ to $7.5 \%, 1.25 \%$ to $8.6 \%$ and $5 \%$ to $8 \%$, respectively), and two series were deposited at fixed silane concentrations (5\% and $7.5 \%$ ) but at various VHF powers (9 to $25 \mathrm{~W}$ and 30 to $70 \mathrm{~W}$, respectively). The $6 \mathrm{~W}$ power series was deposited at $110 \mathrm{MHz}$, the $7 \mathrm{~W}$ power series at $70 \mathrm{MHz}$ while all other series were deposited at $130 \mathrm{MHz}$. A gas purifier was used in order to limit the incorporation into the material of oxygen contaminants coming from the gas source. Layers were either deposited on glass (Schott AF45) for steady-state photoconductivity (SSPC) and SSPG measurements, or on Asahi type U or ZnO-coated glass for SPV measurements. Measurements of $\sigma_{\mathrm{ph}}$ and $\mathrm{L}_{\mathrm{amb}}$ were performed at a generation rate of $\approx 1.7 \times 10^{20} \mathrm{~cm}^{-3} \mathrm{~s}^{-1}$ using a $\mathrm{Kr}$ laser at a wavelength of $647 \mathrm{~nm}$. Defect densities were deduced from the true material optical absorption at an energy of $0.8 \mathrm{eV}$; true absorption value were obtained by taking into account the light scattering effect in absolute constant photocurrent measurements (A-CPM) [10,11]. An overview of the sample deposition conditions and resulting deposition rates is given in Fig. 1 . From this figure we note that some of the samples deposited at high silane concentrations and/or low powers are amorphous or may have a large amorphous fraction.

The layers of the two series grown at the highest powers and therefore at the highest deposition rates (i.e. the $7.5 \%$ silane concentration power series and $30 \mathrm{~W}$ dilution series) were also incorporated (using identical deposition conditions) as i-layers of n-i-p cells. These samples were deposited on TCO- (transparent conductive oxide-) coated glass substrates (Asahi type U for the power series and $\mathrm{ZnO}$-coated AF45 for the dilution series). The cells were terminated either with $\mathrm{ZnO}$ or ITO (Indium Tin Oxide) top contacts. Transparent contacts on both sides were thus provided for charge collection experiments. All cells of the $7.5 \%$ silane concentration series were approximately $3.5 \mu \mathrm{m}$ thick, while the samples from the $30 \mathrm{~W}$ series were all between 2.0 and $2.45 \mu \mathrm{m}$. Current vs. voltage measurements were made under air mass 1.5 (AM1.5) conditions at $100 \mathrm{~mW} / \mathrm{cm}^{-2}$, using a two-source solar simulator.
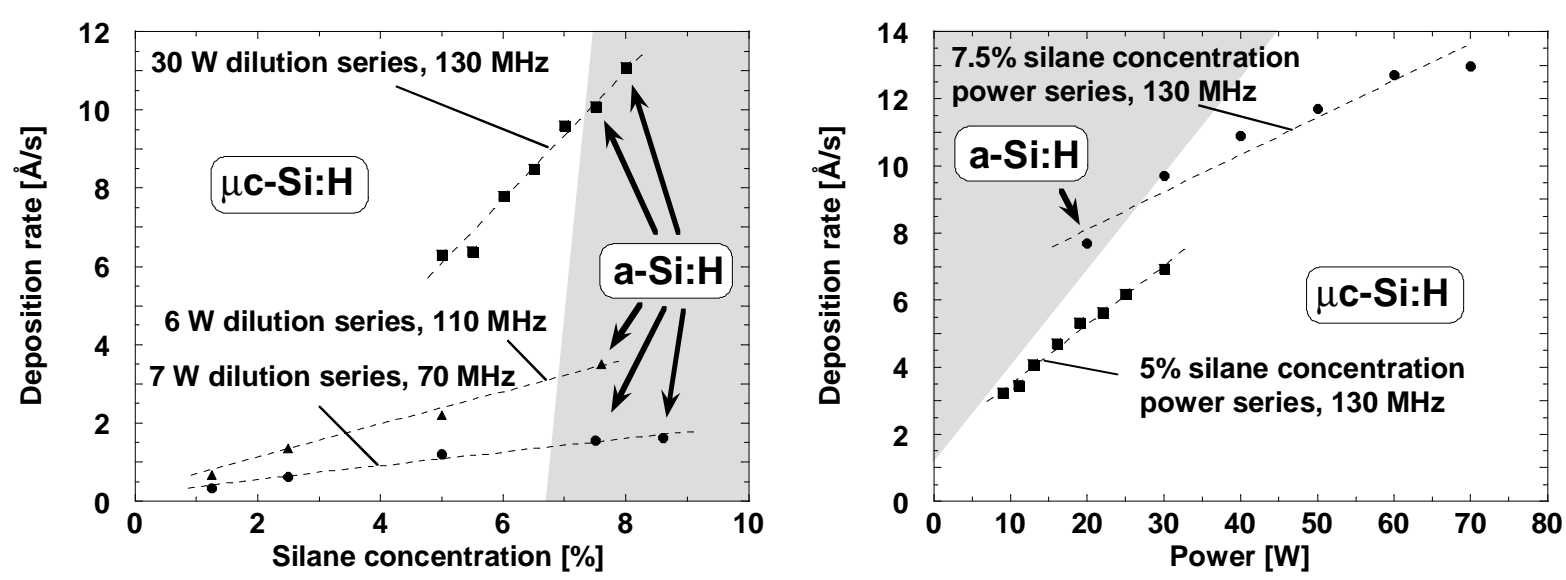

Figure 1: Deposition rate as a function of silane concentration for 3 series of samples deposited at 6,7 and $30 \mathrm{WVHF}$ power (left), and deposition rate as a function of VHF power for 2 series of samples deposited at 5 and $7.5 \%$ silane concentration (right). The transition between amorphous and microcrystalline material (as seen in optical absorption data) is schematically indicated. 


\section{RESULTS AND DISCUSSION}

\section{$\underline{\text { Structural properties }}$}

As already mentioned in the introduction, hydrogen dilution plays an important role in the growth. Transmission electron microscopy (TEM) characterisation of the dilution series deposited at $7 \mathrm{~W}$ (and $70 \mathrm{MHz}$ ) reveals a large change in the microstructure of the material with the change in silane concentration in $\mathrm{H}$ [17], as represented schematically in figure 2. With increasing $\mathrm{H}$ dilution, the crystallite length increases from $30 \mathrm{~nm}$ to several hundreds of nanometers, while the diameter of the crystallites only increases from $8 \mathrm{~nm}$ to $25 \mathrm{~nm}$. The increase of crystallite length results also in an increase of the surface roughness as measured by atomic force microscopy (AFM, see Fig. 2). All samples exhibit a pronounced preferential orientation in the $\langle 220\rangle$ direction, as shown in figure 3 for the $6 \mathrm{~W}$ dilution series and for the $7.5 \%$ power series, although this texture decreases with silane concentration in the case of the $7 \mathrm{~W}$ series [17]. Because of the favourable influence of VHF plasma conditions on crystal growth, the transition from amorphous to microcrystalline growth becomes relatively sharp for VHF deposition conditions [19], and the amorphous tissue content is here lower that $10 \%$ for samples deposited at silane concentrations below 6\% [20].

\section{AFM:}

surface roughness

$$
\mathrm{Sq}=40 \mathrm{~nm} \quad \mathrm{Sq}=18 \mathrm{~nm} \quad \mathrm{Sq}=17 \mathrm{~nm} \quad \mathrm{Sq}=16 \mathrm{~nm} \quad \mathrm{Sq}=4 \mathrm{~nm}
$$

\section{TEM:}

size and shape of the crystallites

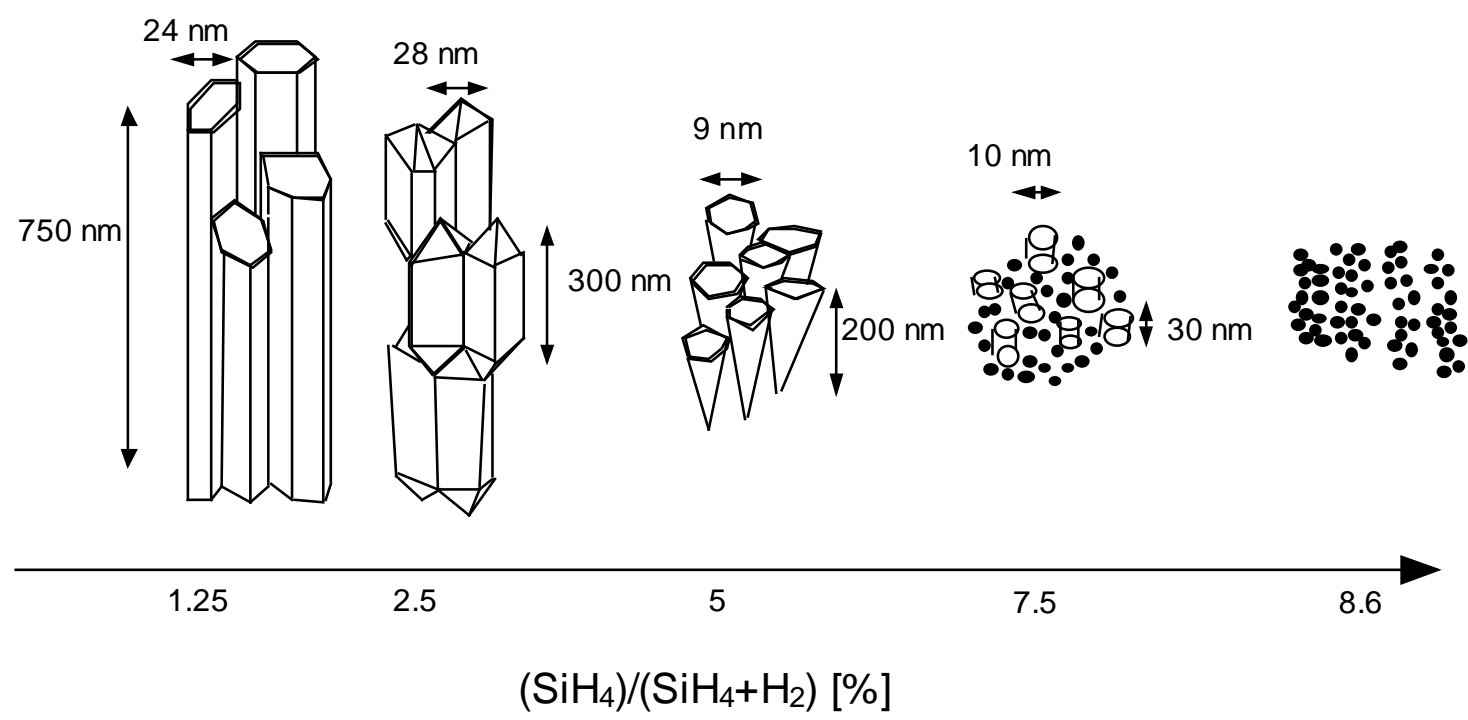

Figure 2: Schematical representation of the evolution of the microstructure of layers as a function of the silane concentration in the plasma gas phase for a series deposited at $7 \mathrm{WVHF}$ power and $70 \mathrm{MHz}$. The small black dots represent the amorphous phase [17]. 

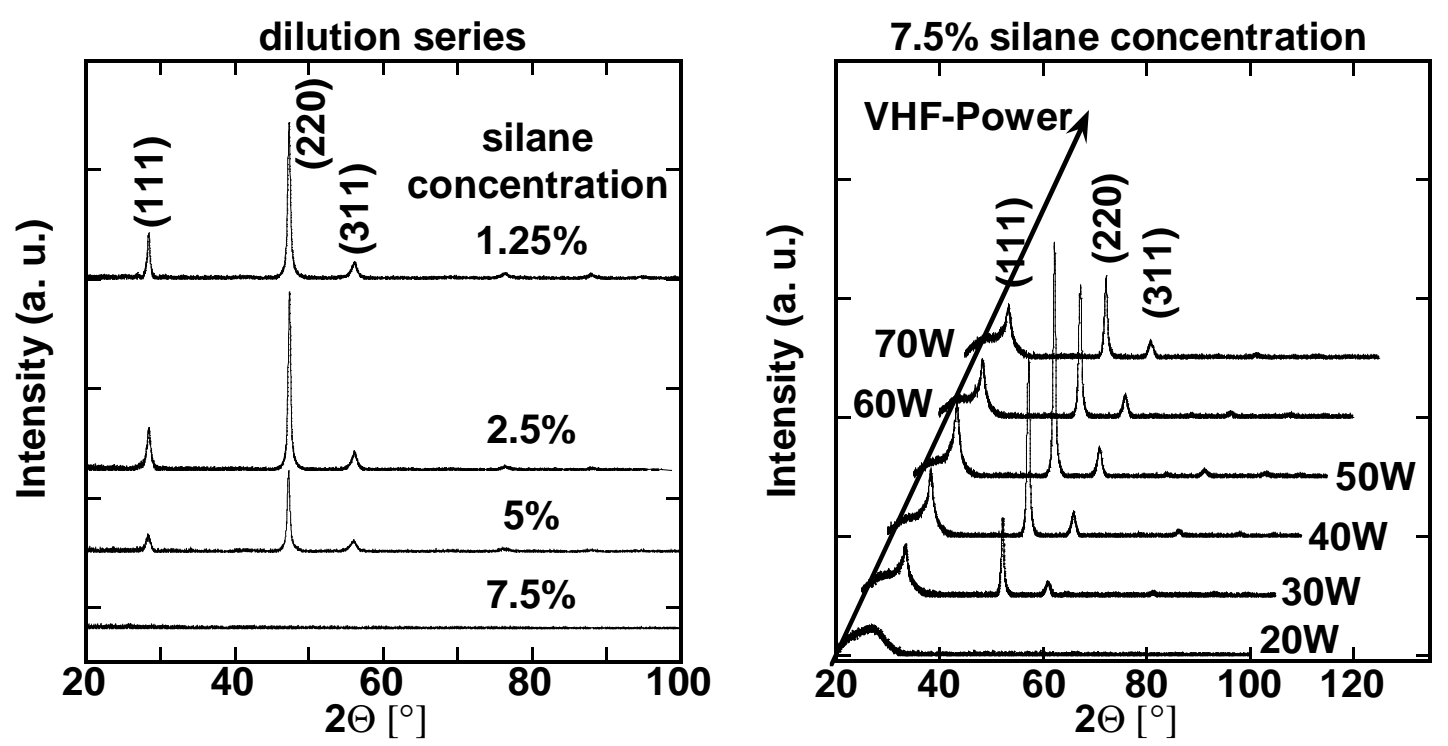

Figure 3: X-ray diffraction (XRD) patterns for samples of the dilution series deposited at $6 \mathrm{~W}$ (110 MHz), as well as for a power series of samples deposited with a silane concentration of $7.5 \%$. For all $\mu \mathrm{c}$-Si:H samples, a clear preferential growth along the $\langle 220\rangle$ direction is observed. XRD data for the $7 \mathrm{WVHF}$ dilution series and 5\% power series are similar and can be found in Ref.17, respectively Refs. 22, 30.

\section{Coplanar transport properties}

Dark conductivity $\sigma_{\mathrm{d}}$ data for the silane concentration and power series is plotted in figure 4 . With increasing silane concentration or increasing power, $\sigma_{\mathrm{d}}$ decreases, except for the $7.5 \%$ silane concentration series. While the strong drop in $\sigma_{\text {dark }}$ close to the transition regime (around $7 \%$, see Fig.1, left) is given by the increasing amorphous fraction in the material, the variation at lower silane concentration is due to a shift of the Fermi level position which is in general induced by a change in impurity incorporation. A variation in the deposition rate modifies the
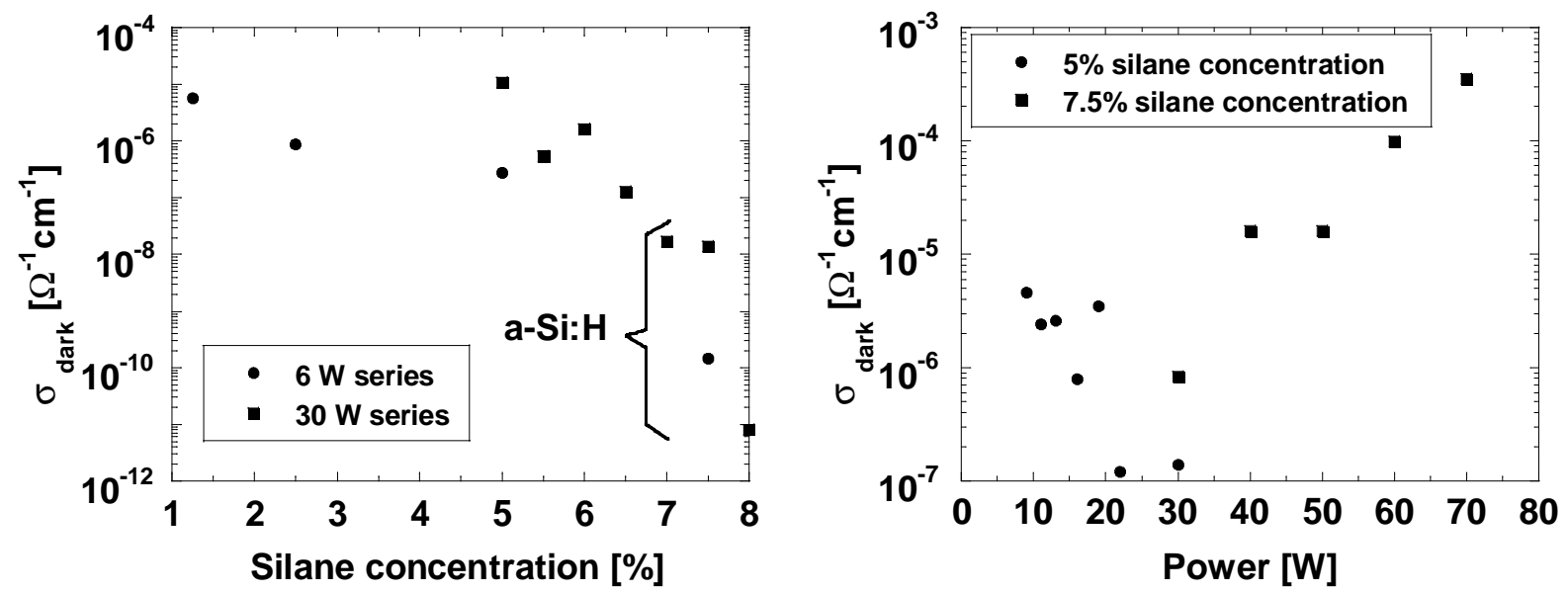

Figure 4: Dark conductivity $\sigma_{\text {dark }}$ as a function of silane concentration for 2 series of samples deposited at 6 and $30 \mathrm{WVHF}$ power (left), and $\sigma_{\text {dark }}$ as a function of VHF power for 2 series of samples deposited at 5 and $7.5 \%$ silane concentration (right). Samples deposited at silane concentration $\geq 7 \%$ and VHF powers $\leq 30 \mathrm{~W}$ are partially or totally amorphous while all other are microcrystalline. 
incorporation of oxygen atoms which act as n-type dopants. A higher deposition rate means a reduced impurity incorporation from the outgasing of the reactor [21]. However, in the case of the $5 \%$ silane concentration series, the oxygen content (as observed by SIMS) remains relatively constant with values between $3 \times 10^{18}$ and $7 \times 10^{18} \mathrm{~cm}^{-3}$; the variations in $\sigma_{\text {dark }}$ depends here on the change in defect density (see Fig. 7) which affects the position of the Fermi level. In the case of the $7.5 \%$ silane concentration, a large oxygen content was observed (by SIMS), which built up mainly after deposition by subsequent oxygen incorporation through the cracks present between the crystallites ("post-oxydation effect") [22].
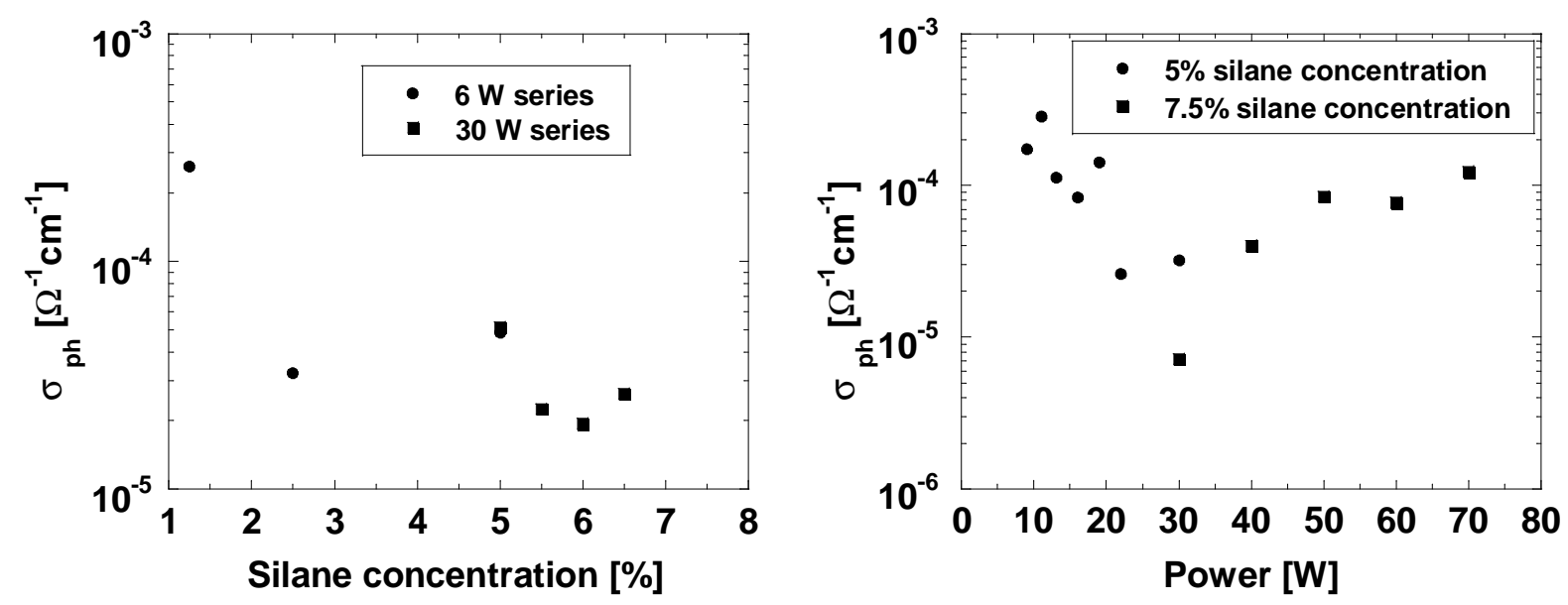

Figure 5: Photoconductivity $\sigma_{p h}$ as a function of silane concentration for 2 series of $\mu c-S i: H$ samples deposited at 6 and $30 \mathrm{~W} V \mathrm{VHF}$ power (left), and $\sigma_{\text {ph }}$ as a function of power for 2 series of samples deposited at 5 and $7.5 \%$ silane concentration (right)

In figure 5, photoconductivity $\sigma_{\mathrm{ph}}$ data for the same two dilution and two power series are plotted. By comparing $\sigma_{\mathrm{ph}}$ with the $\sigma_{\text {dark }}$ values indicated in figure 4 , it is quite obvious that $\sigma_{\mathrm{ph}}$ depends to a large extent in $\sigma_{\text {dark }}$, and as a consequence on the position of the Fermi level. To better illustrate this dependency, mobility $\mathrm{x}$ recombination time products for both electrons
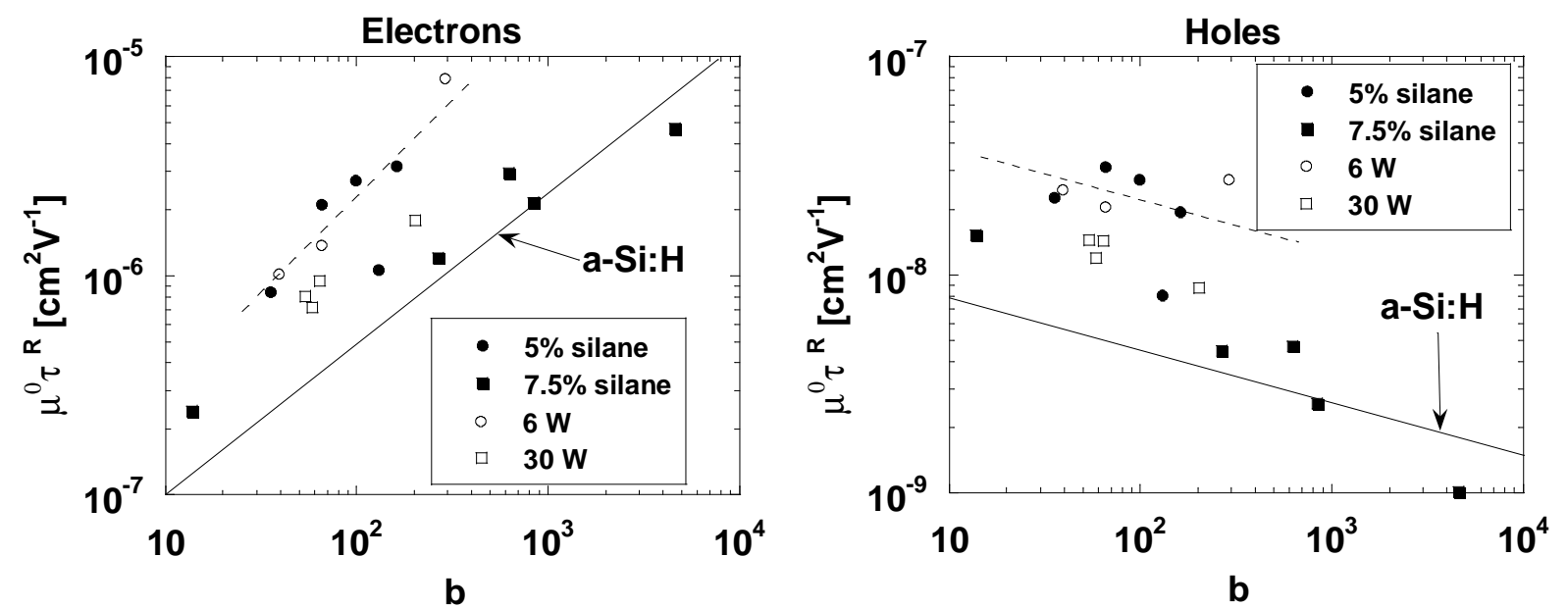

Figure 6: Mobility x recombination time product $\mu^{0} \tau^{R}$ as a function of b for the electrons (left) and for the holes (right), for 4 series of $\mu c$-Si:H samples. $b$, which is given by the ratio of the free carriers densities times the ratio of their respective band mobilities, is another indication of the Fermi level position $E_{F}\left(b \approx 1\right.$ for a "truly" intrinsic sample with $E_{F}$ at midgap). The typical values of $\mu^{0} \tau^{R}$ obtained for a-Si:H samples are also indicated, as well as the trends for $\mu c-S i: H$ samples deposited at low deposition rates (low VHF power). 


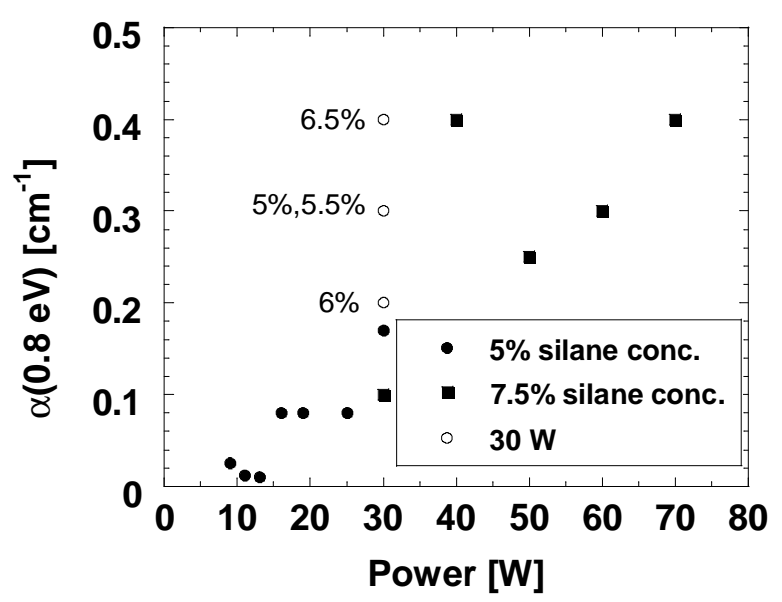

Figure 7: "True" optical absorption coefficient $\alpha(0.8 \mathrm{eV})$ at an energy of $0.8 \mathrm{eV}$ for three series of $\mu c$-Si:H samples. $\alpha(0.8 \mathrm{eV})$ can be used as a measure of the defect density in the material, and was deduced from A-CPM; the qualification "true" indicates that the experimentally measured absorption coefficient was corrected for the effect of light scattering [10,11].

(deduced from $\sigma_{\mathrm{ph}}$ ) and holes electrons (deduced from $\mathrm{L}_{\mathrm{amb}}$ ) are showed in figure 6 as a function of the Fermi level position, the latter being monitored by the value of the parameter $b$. $b$ was originally defined for amorphous hydrogenated silicon (a-Si:H) [23]; it is given by the ratio of free carrier densities times the ratio of band mobilities, $\mathrm{b}=\left(\mu_{\mathrm{n}}^{0} / \mu_{\mathrm{p}}^{0}\right)\left(\mathrm{n}_{\mathrm{f}} / \mathrm{p}_{\mathrm{f}}\right)$. $\mathrm{b}$ has the advantage that it can be deduced directly from a combination of SSPC and SSPG measurements [23]. One can here observe that transport in $\mu \mathrm{c}-\mathrm{Si}: \mathrm{H}$ layers tends to be better than that in a-Si:H layers for comparable generation levels and for comparable position of the Fermi level (i.e. for a similar value of $b$ ). Variations of $\sigma_{\mathrm{ph}}$ or $\mathrm{L}_{\mathrm{amb}}$ as a function of $\mathrm{b}$ for $\mu \mathrm{c}-\mathrm{Si}: \mathrm{H}$ remain, at least for samples deposited at low power (with limited post-oxidation), comparable to those in a-Si:H, as also observed by Droz et al. [24].

In order to explain the disparity between transport properties of samples exhibiting the same value of $b$, the defect densities of the various samples were also estimated from the determination of the true optical absorption coefficient $\alpha$ at an energy of $0.8 \mathrm{eV}[10,11]$ as plotted in figure 7 .
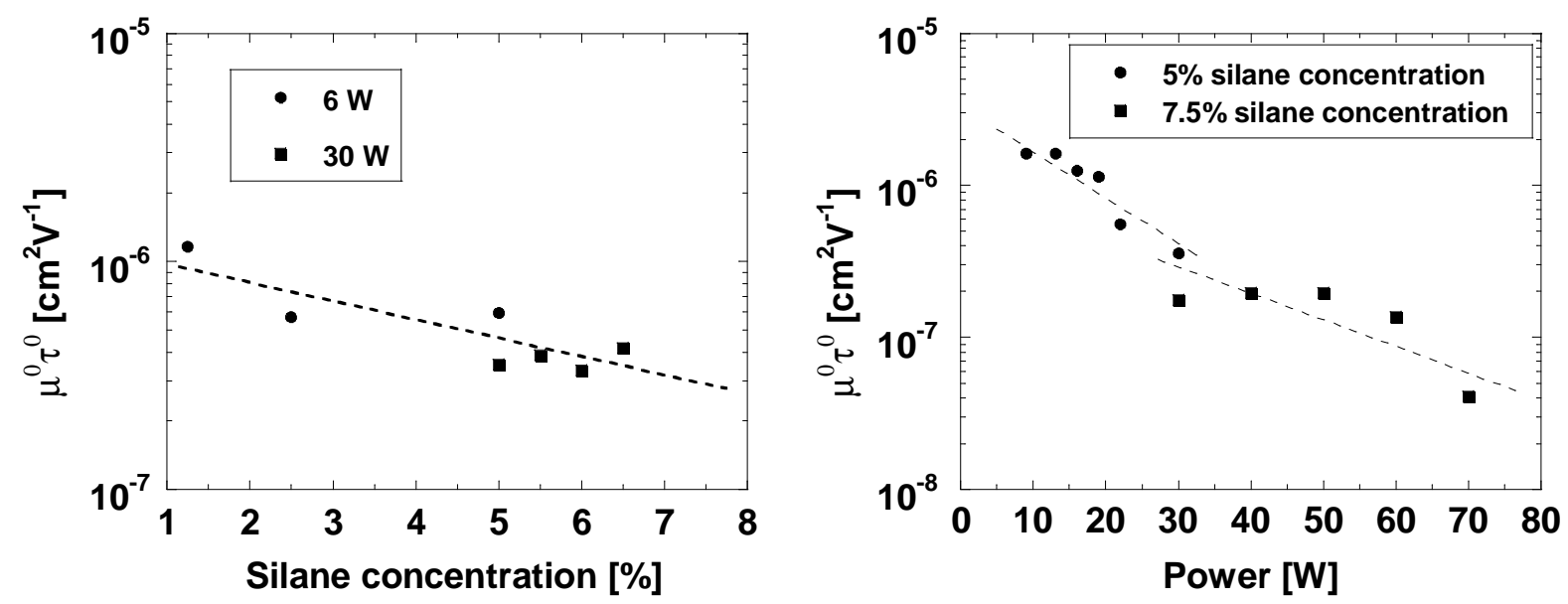

Figure 8: Quality parameter $\mu^{0} \tau^{0}$ as a function of silane concentration for 2 series of $\mu c-S i: H$ samples deposited at 6 and $30 \mathrm{~W} V H F$ power (left), and $\mu^{0} \tau^{\varrho}$ as a function of power for 2 series of samples deposited at 5 and $7.5 \%$ silane concentration (right). Dashed lines are guides for the eyes. 
An approximate value of the defect density can be obtained by multiplying $\alpha(0.8 \mathrm{eV})$ with the calibration factor of $1.6 \times 10^{17}$ defects $/ \mathrm{cm}^{-2}[15]$.

In order to be able to compare in a more significant way transport properties of samples that exhibit different positions of the Fermi level, one can combine both $\sigma_{\mathrm{ph}}$ and $\mathrm{L}_{\mathrm{amb}}$, and introduce thereby a quality parameter $\mu^{0} \tau^{0}$ which is independent of the Fermi level position (i.e.

independent of the value of b). Such a procedure, which was developed for the case of a-Si:H [23] seems indeed also valid for $\mu \mathrm{c}-\mathrm{Si}: \mathrm{H}$, given the similarities in the transport processes [24, 25, 26]. As seen in figure 8, discrepancies between the various series disappear and we observe a smooth variation of $\mu^{0} \tau^{0}$ as a function of both the silane concentration and of the VHF power. If we further plot $\mu^{0} \tau^{0}$ as a function of $\alpha(0.8 \mathrm{eV})$ (see Fig. 9), we observe an approximate powerlaw dependency with a power-law factor of -1 , or said in other words, we see that $\mu^{0} \tau^{0}$ varies mainly with defect density.

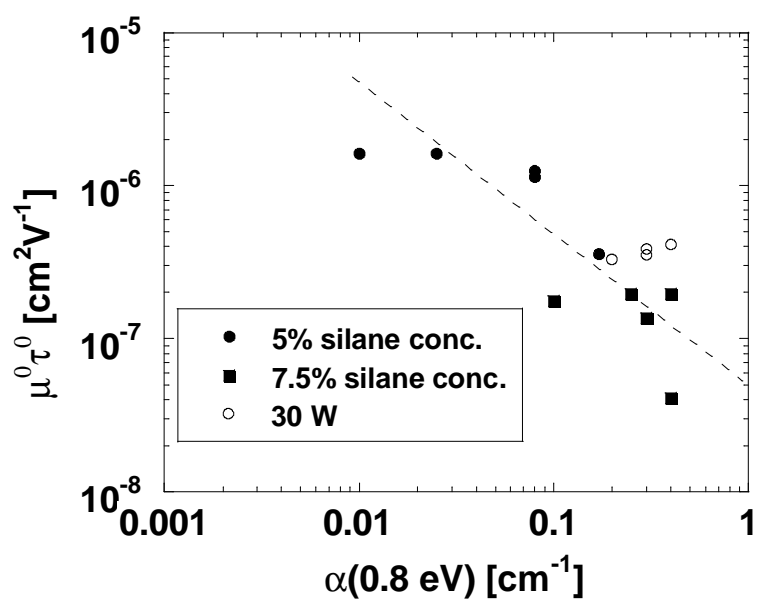

Figure 9: Quality parameter $\mu^{0} \tau^{0}$ as a function of the "true" optical absorption coefficient $\alpha(0.8 \mathrm{eV})$ at an energy of $0.8 \mathrm{eV}$, the latter being proportional to the defect density. The dashed line is given as a guide for the eye; it corresponds to a power-law with a-1 exponent.

At this stage, we were, thus, able to demonstrate that coplanar transport properties in $\mu \mathrm{c}-\mathrm{Si}: \mathrm{H}$ layer, prepared by VHF-GD under a large range of deposition conditions, can be explained in terms of defect densities and impurity content alone. The important change in the microstructure, i.e. crystallite shape and size, upon hydrogen dilution does not play here an important role. This observation strongly suggests that transport is not controlled by the crystallites but rather by the grain boundaries or by the amorphous tissue between the grains. It also could explain why transport in $\mu \mathrm{c}-\mathrm{Si}: \mathrm{H}$ is so similar to the one in a-Si:H.

\section{Transversal transport properties}

All transport properties were so far investigated in the coplanar configuration (i.e. transport parallel to the surface of the sample. As seen in figures 2 and 3, our $\mu \mathrm{c}-\mathrm{Si}: \mathrm{H}$ layers are composed of elongated microcrystallites which extend in the direction perpendicular to the substrate. Furthermore, these microcrystallites reveal a strong $\langle 220\rangle$ texture. We could therefore expect a possible anisotropy in the transport properties. Such an anisotropy can be checked by comparing $\mathrm{L}_{\mathrm{amb}}$ (coplanar transport) with the diffusion length $\mathrm{L}_{\mathrm{D}}$ measured by the SPV technique (transversal transport). For high-quality samples deposited at low deposition rate (i.e. at low values of the VHF power), we observe a marked discrepancy between $L_{a m b}$ with $L_{D}$ which confirms the presence of an anisotropy in these films (see Fig. 10). This anisotropy was also observed by comparing DC and AC conductivity for most samples of the 5\% series, but it was not observed in any of the samples of the $7.5 \%$ silane concentration series [27]. Note that no 
change in the XRD pattern as a function of VHF power was observed within the $5 \%$ silane concentration series. For samples deposited at higher rates (samples of the $30 \mathrm{~W}$ VHF power deposited at silane concentration between 5 and $7 \%$ ), all $\mathrm{L}_{\mathrm{D}}$ values are between 60 and $100 \mathrm{~nm}$ while $\mathrm{L}_{\mathrm{amb}}$ shows values between 180 and $240 \mathrm{~nm}$. Such a discrepancy is not yet understood, but one of the possible reasons could be the large oxygen content (due to post-oxidation) located near the film surface. This could strongly reduce the measured value of $L_{D}$, because SPV probes the region near the surface. In any case, SPV is expected to be much more surface sensitive than SSPG. Because of this, AC conductivity may be a better tool for analysing the anisotropy [28].

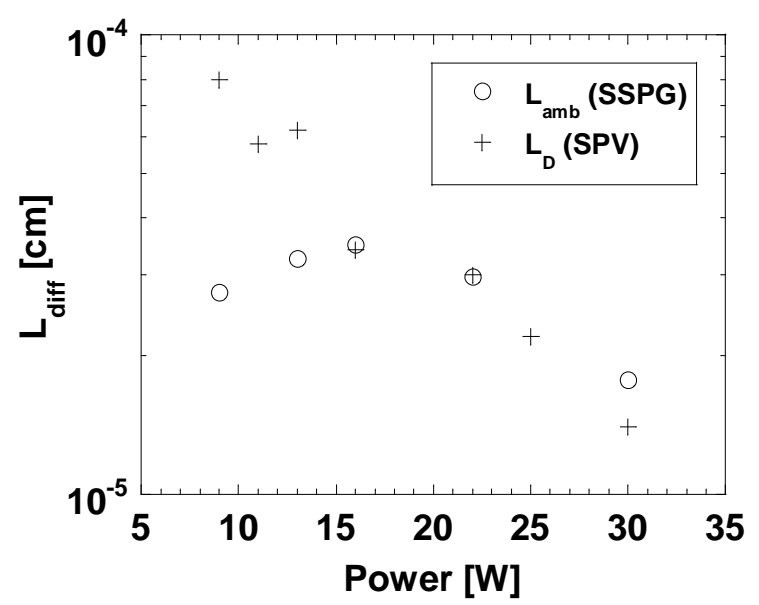

Figure 10: Comparison between the diffusion length $L_{D}$ (measured by SPV) and the ambipolar diffusion length $L_{a m b}$ (measured by SSPG) on the power series of $\mu \mathrm{c}$-Si:H layers deposited at $5 \%$ silane concentration.

A further aspect of this anisotropy question is related to the observed structural variation in $\mu \mathrm{c}-\mathrm{Si}: \mathrm{H}$ layers as a function of substrate material. It is well known that $\mu \mathrm{c}-\mathrm{Si}: \mathrm{H}$ growth not only depend on the deposition conditions, but also on the underlying substrate [7,9]. Therefore, $\mu \mathrm{c}-\mathrm{Si}$ :H layers deposited on glass substrate (for coplanar transport measurements) could very well be quite different from the layers deposited under identical deposition conditions on conductive substrates (such as metal-coated glass or a transparent conductive oxide). For example, the rms value of the surface roughness (determined from AFM imaging) of $\mu \mathrm{c}-\mathrm{Si}: \mathrm{H}$ sample deposited at $30 \mathrm{~W}$ and $5 \%$ silane concentration is $25 \mathrm{~nm}$ on glass, but only $18 \mathrm{~nm}$ on flat $\mathrm{ZnO}: \mathrm{Al}$ coated glass; such a change reveals, in general, a structural change in the material (see also Fig. 2). Furthermore, intrinsic material grown at silane concentration of 5 to $6 \%$ has a structural morphology similar to material grown at lower silane concentrations (see pictures in Refs. 17 and 29). Despite this fact, a correlation between coplanar and transversal transport is still observed for most samples (see Fig. 10), supporting the idea that the structure itself plays a marginal role for the transport properties. A last point in favour of this argument, is the fact that steady-state (coplanar) transport and transient (transversal) transport measured by time of flight (TOF) for co-deposited samples have a very similarly relation as is also observed in a-Si:H, namely minority carrier steady-state and transient $\mu \tau$ values are almost equal while majority carrier steady-state and transient $\mu \tau$ values differ by roughly one order of magnitude [30].

\section{$\underline{\text { Solar cells }}$}

As steady-state transport in layers can indeed be described by the quality parameter $\mu^{0} \tau^{0}$ and is not too influenced by the underlying substrate or growth conditions, one should observe a correlation between $\mu \mathrm{c}-\mathrm{Si}: \mathrm{H}$ cell efficiency and the quality parameter $\mu^{0} \tau^{0}$. As seen in figure 11 , such a correlation is indeed observed for the two series on which both the layers and the 
corresponding cells were available. Note, that the relatively low efficiencies of these cells is due to the absence of an infra-red light back reflector (the back reflector was left out in order to allow illumination through the back contact for detailed cell analysis). Due to the important scattering of the layer quality parameter $\mu^{0} \tau^{0}$ data as a function of defect density (see Fig. 9), no correlation is found between cell efficiency and $\alpha(0.8 \mathrm{eV})$, as shown in figure 12. The latter observations underlines the usefulness of the quality parameter $\mu^{0} \tau^{0}$ as tool for $\mu \mathrm{c}-\mathrm{Si}: \mathrm{H}$ cell development. However, the absence of correlation between efficiency and defect density is disturbing.

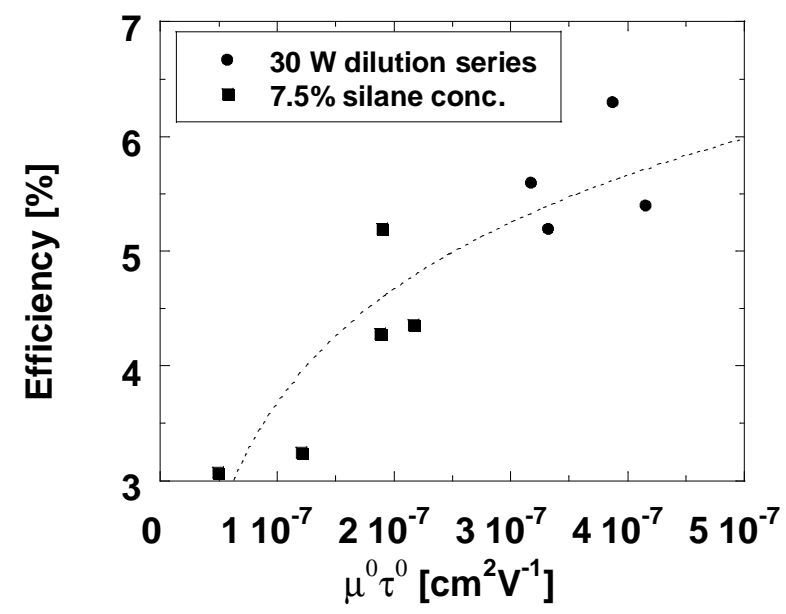

Figure 11: Solar cell efficiency as a function of the quality parameter $\mu^{0} \tau^{0}$ of corresponding $i$-layers for the $30 \mathrm{~W}$ VHF power dilution series and the $7.5 \%$ silane concentration power series.

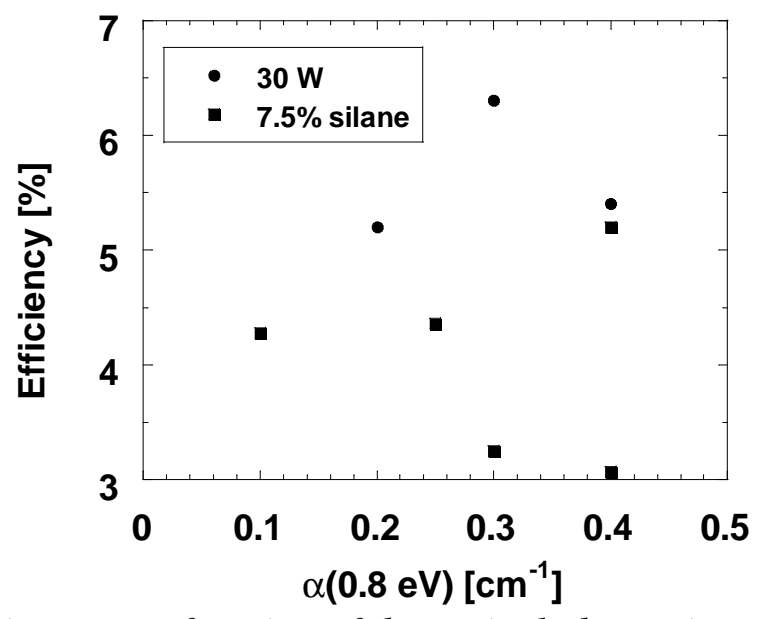

Figure 12: Solar cell efficiency as a function of the optical absorption coefficient $\alpha(0.8 \mathrm{eV})$ of corresponding $i$-layers for the $30 \mathrm{~W}$ VHF power dilution series and the $7.5 \%$ silane concentration power series. No correlation is found between cell efficiency and $\alpha(0.8 \mathrm{eV})$.

Almost all $\mu \mathrm{c}-\mathrm{Si}: \mathrm{H}$ layers and cells deposited in our group under VHF conditions with hydrogen dilution exhibit a $<220>$ texture. With this material single-junction solar cell efficiencies up to $8.5 \%$ have been obtained. On the other hand, Vetterl et al. have obtained similar cell efficiencies [31] with $\mu c-S i: H$ material also deposited under VHF conditions and hydrogen dilution, but where no preferential orientation is found [7]. This fact is a further support for the weak influence of material microstructure on the transport properties.

However, Dubail et al. were able to demonstrate the effect of the hydrogen to silane dilution ratio on the $\mu \mathrm{c}-\mathrm{Si}: \mathrm{H}$ structure within a p-i-n solar cell (more exactly on the material structure at the $\mathrm{p}-\mathrm{i}$ interface where the initial growth of the i-layer takes place), as well as the influence of 
this on the cell performance [29]. This illustrates very well the difficulty we face for understanding transport in solar cells, which originate in the fact that both the bulk of the i-layer, as well as the interfaces may play a role, and both can be affected by the growth of the $\mu \mathrm{c}-\mathrm{Si}: \mathrm{H}$ material. Therefore, direct and straightforward correlation between material quality and cell performance will always be difficult.

\section{CONCLUSIONS}

In this study, we have shown that transport properties of $\mu \mathrm{c}-\mathrm{Si}: \mathrm{H}$ deposited under a wide range of hydrogen to silane dilution ratios and of VHF power values depend mainly on the defect density and on the position of the Fermi level (which is related to the impurity content in the films and mainly to oxygen atoms density), and can be conveniently described by the $\mu^{0} \tau^{0}$ quality parameter. These experimental facts strongly suggest that transport in $\mu \mathrm{c}-\mathrm{Si}: \mathrm{H}$ is mainly controlled by amorphous silicon tissue present at the grain boundaries or the grain boundaries themselves. This conclusion seems in most samples valid not only for coplanar transport, but also for transport perpendicular to the substrate (transversal transport). An anisotropy in the transport properties is found on a few samples deposited at low VHF power values with very low defect density. However, in this last case, no particular differences were found in the structural properties (with respect to other layers) to identify and explain such an anisotropy.

As far as cells are concerned, a good agreement is found (as expected from the layer analysis) between intrinsic layer quality parameters $\mu^{0} \tau^{0}$ and cell efficiency, but the situation here is less "clear cut" due to the important role of interfaces on solar cell performance. One should note that initial growth of the $\mu \mathrm{c}-\mathrm{Si}: \mathrm{H}$ i-layer critically affects the interface properties and consequently the whole device performances. Preliminary results shows that a change in $\mu \mathrm{c}-\mathrm{Si}: \mathrm{H}$ structural properties at the $\mathrm{p}-\mathrm{i}$ interface of $\mathrm{p}-\mathrm{i}-\mathrm{n}$ cells, induced by a variation of the hydrogen to silane dilution ratio, indeed affects the performance [29].

\section{ACKNOWLEDGEMENTS}

This work was supported by the Swiss Federal Renewable Energy Program (grant 19431) and the Swiss National Foundation grant FN-45696 and FN-52337. The authors thank also Dr. Jan Kocka for valuable suggestions and help regarding the SPV measurements.

\section{REFERENCES}

1. S. Veprek, V. Marecek, Solid-State Electron., 11, 683 (1968).

2. S. Veprek, Z. Iqbal, H.R. Oswald, A.P. Webb, J. Phys., C 14, 295 (1981).

3. S. Veprek, Z. Iqbal, R.O, Kühne, P. Capezzuto, F.-A. Sarott, J.K. Gimzewski, J. Phys., C 16, 6241 (1983).

4. S. Veprek, M. Heintze, F.-A. Sarott, M. Jurcik-Rajman, P. Willmott, Mat. Res. Soc. Symp. Proc., 118, 3 (1988).

5. J. Meier et al., Proc. of the $2^{\text {nd }}$ World Conf. on Photovoltaic Solar Energy Conversion, Vienna, 375 (1998).

6. K. Saito, M. Sano, K. Matzuda, T. Kondo, M. Higasikawa, T.. Kariya, Technical Digest of the Int. PV Science and Eng. Conf. PVSEC-11, Hokkaido, Japan, 229 (1999).

7. M. Luysberg, P. Hapke, R. Carius, F. Finger, Phil. Mag. A, 75, 31 (1997).

8. C. Ross, J. Herion, H. Wagner, J. of Non-Cryst. Sol., 266-269, (2000) (in press).

9. M. Kondo, Y. Toyoshima, A. Matsuda, K. Ikuta, J. Appl. Phys., 80, 6061 (1996).

10. A. Poruba, Z. Remes, J. Springer, M. Vanecek, A. Fejfar, J. Kocka, J. Meier, P. Torres, A. Shah, Proc. of the $2^{\text {nd }}$ World Conf. on Photovoltaic Solar Energy Conversion, Vienna, 781 (1998).

11 A. Poruba, A. Feijfar, O. Salyk, M. Vanecek, J. Kocka, J. of Non-Cryst. Sol., 266-269, (2000) (in press). 
12. K. Lips, P. Kanschat, D. Will, C. Lerner, W. Fuhs, J. of Non-Cryst. Sol., 227-230, 1021 (1998).

13. D. Ruff, H. Mell, L. Toth, I. Sieber, W. Fuhs, J. of Non-Cryst. Sol., 227-230, 1011 (1998).

14. N. Wyrsch, L. Feitknecht, C. Droz, P. Torres, A. Shah, A. Poruba and M. Vanecek, J. of Non-Cryst. Sol., 266-269, 1099 (2000) (in press).

15. M. Vanecek, A. Poruba, Z. Remes, J. Rosa, S. Kamba, V. Vorlicek, J. Meier, A. Shah, J. of Non-Cryst. Sol., 266-269, (2000) (in press).

16. F. Finger, J. Müller, C. Malten, R. Carius, H. Wagner, J. of Non-Cryst. Sol., 266-269, (2000) (in press).

17. E. Vallat-Sauvain, U. Kroll, J. Meier, A. Shah, J. of Appl. Phys., 87, 3137 (2000).

18. U. Kroll, J. Meier, A. Shah, S. Mikhailov, J. Weber, J. of Appl. Phys., 80, 4971 (1996).

19. U. Kroll, J. Meier, P. Torres, J. Pohl, A. Shah, J. of Non-Cryst. Sol., 227-230, 68 (1998).

20. P. Torres, Ph.D thesis, UFO Atelier für Gestaltung \& Verlag, Band 352, ISBN 3-930803-518, (1998).

21. P. Torres, J. Meier, R. Flückiger, U. Kroll, J. Anna Selvan, H. Keppner, A. Shah, S.D. Littlewood, I.E. Kelly, P. Giannoulès, Appl. Phys. Lett., 69, 1373 (1996).

22. M. Goerlitzer, P. Torres, N. Beck, N. Wyrsch, H. Keppner, J. Pohl, A. Shah, J. of NonCryst. Sol., 227-230, 996 (1998).

23. N. Beck, N. Wyrsch, C. Hof, A: Shah, J. of Appl. Phys., 79, 9361 (1996).

24. C. Droz, M. Goerlitzer, N. Wyrsch, A. Shah, J. of Non-Cryst. Sol., 266-269, (2000) (in press).

25. M. Goerlitzer, P.Torres, C. Droz, A. Shah, Sol. Energy Mat. and Sol. Cells, 60, 195 (2000).

26. P. Kanschat, K. Lips, W. Fuhs, J. of Non-Cryst. Sol., 266-269, (2000) (in press).

27 J. Kocka, A. Feijfar, H. Stuchlikova, B. Rezek, A. Poruba, M. Vanecek, P.Torres, J. Meier, N. Wyrsch, A. Shah, A. Matsuda, Proc. of the $2^{\text {nd }}$ World Conf. on PV Solar Energy Conversion, Vienna, 785 (1998).

28. J. Kocka, H. Stuchlikova, J. Stuchlik, V. Svrcek, P. Fojtik, I. Pelant, A. Feijfar, J. of NonCryst. Sol., 266-269, (2000) (in press).

29. J. Dubail, E. Vallat-Sauvain, J. Meier, S. Dubail, L. Feitknecht, U. Kroll and A. Shah, this issue.

30. N. Wyrsch et al., Polycrystalline Semiconductors V - Bulk Materials, Thin Films, and Devices, J.H. Werner, H.P. Strunk, H.W. Schock eds., in Series "Solid State Phenomena", Scitech Publ., Uettikon am See, Switzerland, Vol. 67-68, 89-100 (1999).

31. O. Vetterl, F. Finger, R. Carius, P. Hapke, L. Houben, O. Kluth, A. Lambertz, A. Mück, B. Rech, H. Wagner, Sol. Energy Mat. and Sol. Cells, 62, 91 (2000). 